\title{
Trolox contributes to Nrf2-mediated protection of human and murine primary alveolar type II cells from injury by cigarette smoke
}

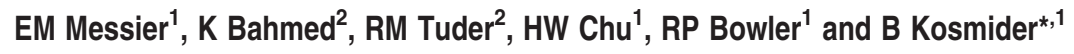

Cigarette smoke (CS) is a main risk factor for chronic obstructive pulmonary disease (COPD). Oxidative stress induced by CS causes DNA and lung damage. Oxidant/antioxidant imbalance occurs in the distal air spaces of smokers and in patients with COPD. We studied the effect of oxidative stress generated by CS both in vivo and in vitro on murine primary alveolar type II (ATII) cells isolated from nuclear erythroid 2-related factor-2 (Nrf2) ${ }^{-I-}$ mice. We determined human primary ATII cell injury by CS in vitro and analyzed ATII cells isolated from smoker and non-smoker lung donors ex vivo. We also studied whether trolox (watersoluble derivative of vitamin E) could protect murine and human ATII cells against CS-induced DNA damage and/or decrease injury. We analyzed oxidative stress by 4-hydroxynonenal expression, reactive oxygen species (ROS) generation by Amplex Red Hydrogen Peroxide Assay, Nrf2, heme oxygenase 1, p53 and P53-binding protein 1 (53BP1) expression by immonoblotting, Nrf2 nuclear translocation, Nrf2 and p53 DNA-binding activities, apoptosis by terminal deoxynucleotidyl transferase-mediated dUTP nick-end labeling assay and cytokine production by ELISA. We found that ATII cells isolated from Nrf2 ${ }^{-1-}$ mice are more susceptible to CS-induced oxidative DNA damage mediated by p53/53BP1 both in vivo and in vitro compared with wild-type mice. Therefore, Nrf2 activation is a key factor to protect ATII cells against injury by CS. Moreover, trolox abolished human ATII cell injury and decreased DNA damage induced by CS in vitro. Furthermore, we found higher inflammation and p53 mRNA expression by RT-PCR in ATIl cells isolated from smoker lung donors in comparison with non-smokers ex vivo. Our results indicate that the Nrf2 and p53 cross talk in ATIl cells affect the susceptibility of these cells to injury by CS. Trolox can protect against oxidative stress, genotoxicity and inflammation induced by CS through ROS scavenging mechanism, and serve as a potential antioxidant prevention strategy against oxidative injury of ATII cells in CS-related lung diseases.

Cell Death and Disease (2013) 4, e573; doi:10.1038/cddis.2013.96; published online 4 April 2013

Subject Category: Experimental Medicine

Cigarette smoke (CS) is the main risk factor for the development of chronic obstructive pulmonary disease (COPD). ${ }^{1}$ There is no effective therapy to prevent the progression of this disease. ${ }^{2}$ Oxidative stress induced by CS is the main cause of DNA damage ${ }^{3}$ and defects in DNA damage recognition and repair mechanisms are associated with cancer predisposition. ${ }^{4}$ The tumor suppressor protein p53 is involved in the response to genotoxic stress. P53-binding protein 1 (53BP1) is a major determinant of DNA damage ${ }^{5}$ and is a mediator that relays signals from DNA damage sensors and activates various effectors for the DNA repair. ${ }^{6}$ There is an urgent need to develop new strategies to prevent oxidative lung injury induced by CS.

The nuclear erythroid 2-related factor-2 (Nrf2) transcription factor is a key regulator of the antioxidant response element (ARE)-mediated expression of phase II detoxifying antioxidant enzymes. ${ }^{7-9}$ Nrf2 is ubiquitously expressed throughout the lung but is predominantly found in the epithelium. ${ }^{10}$
The Nrf2-dependent genes have the ability to upregulate antioxidant defenses and decrease lung inflammation and alveolar cell apoptosis. ${ }^{11}$ Pulmonary Nrf2 effector genes bearing AREs include, for example, heme oxygenase 1 $(\mathrm{HO}-1), \mathrm{NAD}(\mathrm{P}) \mathrm{H}$ :quinone oxidoreductase 1 (NQO1) and gamma glutamyl-cysteine ligase catalytic subunit (GCLc) ${ }^{9}$ We selected HO-1 for our analysis because it has been shown to have a central role in the defense against lung inflammatory insults, including CS exposure, ${ }^{11}$ and $\mathrm{HO}-1$ overexpression protects against oxidative stress. ${ }^{12}$ NQO1 and GCLc were found to be involved in pulmonary pathogenesis of rats exposed to CS by microarray analysis. ${ }^{13}$

Antioxidant compounds could have a key role in the protection against CS-induced DNA damage and/or decreasing lung injury. ${ }^{14}$ Vitamin $E$ is known to be one of the most potent lipophilic chain-breaking antioxidants in biological membranes, where it scavenges reactive oxygen species (ROS), inhibits the initiation and chain propagation of

\footnotetext{
${ }^{1}$ Department of Medicine, National Jewish Health, 1400 Jackson Street, Denver, CO 80206, USA and 2University of Colorado School of Medicine, Denver, CO, USA ${ }^{*}$ Corresponding author: B Kosmider, Department of Medicine, National Jewish Health, 1400 Jackson Street, Denver, CO 80206, USA. Tel: + 303 270 2036; Fax: + 303270 2353; E-mail: KosmiderB@ NJHealth.org

Keywords: alveolar type II cells; cigarette smoke; trolox; Nrf2; lung

Abbreviations: ATII, alveolar type II cells; Nrf2, nuclear erythroid 2-related factor-2; ROS, reactive oxygen species; COPD, chronic obstructive pulmonary disease; CS, cigarette smoke; 53BP1, P53-binding protein 1; ARE, antioxidant response element; HO-1, heme oxygenase 1; NQO1, NAD(P)H:quinone oxidoreductase 1; GCLc, gamma glutamyl-cysteine ligase catalytic subunit

Received 17.12.12; revised 02.2.13; accepted 12.2.13; Edited by A Finazzi-Agró
} 
lipid peroxidation, and protects cellular structures against oxidative stress. ${ }^{15}$ Vitamin $E$ is present in the lung and in alveolar type II (ATII) cells. ${ }^{16}$ Because of its ability to decrease oxidative stress and lessen inflammation, vitamin $E$ has been evaluated to improve CS-associated diseases, ${ }^{17}$ for example, COPD and emphysema, ${ }^{18}$ lung tumors, ${ }^{19}$ asthma ${ }^{20}$ and cardiovascular disease. ${ }^{21}$ Trolox is a water-soluble vitamin $E$ analog with a high capacity to capture ROS. It is used as a standard to check the antioxidant capacity of other molecules. $^{22}$

By decreasing oxidant insults to the lung, trolox could modulate the development of chronic lung diseases and lung function decrement. Moreover, higher antioxidant status is associated with lower risk of COPD. ${ }^{23}$ It has been reported that oxidant/antioxidant imbalance occurs in the distal air spaces and in alveolar wall cells of smokers and patients with COPD and emphysema. ${ }^{24,25}$ Therefore, in this study, we focused on human and murine primary ATII cells. As a novel approach, we isolated murine ATII cells from $\mathrm{Nrf}^{-/-}$ and $\mathrm{Nrf}^{+/+}$mice, and purified them using magnetic MicroBeads as we recently reported. ${ }^{26}$ For the first time, we compared the effect of CS both in vitro and in vivo on injury of murine primary ATII cells isolated from $\mathrm{Nrf}^{-/-}$and Nrf2 $2^{+/+}$ mice and human primary ATII cells in vitro. Furthermore, we analyzed freshly isolated human primary ATII cells obtained from smoker and non-smoker lung donors ex vivo. Our hypothesis was that Nrf2 activation is a key factor to protect ATII cells against oxidative injury by $C S$, and that trolox will abolish ATII cell injury, decrease DNA damage and inflammation induced by CS through a ROS scavenging mechanism.

\section{Results}

Trolox and Nrf2 activation decrease inflammation induced by $\mathrm{CS}$ in vivo. $\mathrm{KC}$ and IL-6 levels in bronchoalveolar lavage (BAL) were identified as inflammatory parameters after exposure of $\mathrm{Nrf}^{+/+}$and $\mathrm{Nrf}^{-1-}$ mice to CS in vivo. Their levels were significantly increased in both genotypes exposed to CS in vivo in comparison with the control (Figure 1). However, KC and IL-6 levels were higher in BAL obtained from Nrf2 $2^{-l-}$ than Nrf2 $2^{+l+}$ mice. Treatment with trolox followed by exposure to CS completely abolished the inflammatory response induced by $\mathrm{CS}$ in $\mathrm{Nrf2} 2^{+/+}$mice. This compound also significantly decreased KC and IL-6 levels induced by $\mathrm{CS}$ in $\mathrm{Nrf} 2^{-1-}$ mice in comparison with CS alone. However, KC and IL-6 levels were still higher in comparison with control. Our results indicate that trolox abolishes inflammatory response induced by $\mathrm{CS}$ in $\mathrm{Nrf2} 2^{+/+}$ mice and partially protects $\mathrm{Nrf}^{-/-}$mice against inflammation in vivo.

Trolox and Nrf2 activation protects murine ATII cells against injury induced by $\mathrm{CS}$ in vivo. We analyzed protein expression in lung tissue obtained from $\mathrm{Nrf2}^{-1-}$ and Nrf2 ${ }^{+l+}$ mice exposed to CS in vivo (Figure 2, Panel A). We compared oxidative stress using 4-hydroxynonenal (4-HNE), which is a product of lipid peroxidation. We found significantly higher Nrf2, NQO1, GCLc and 4-HNE levels in $\mathrm{Nrf} 2^{+/+}$mice exposed to $\mathrm{CS}$ and their expressions were decreased by trolox administration. We also observed high expressions of p53 and 4-HNE induced by CS in $\mathrm{Nrf2}{ }^{-1-}$ mice, and their decrease by exposure to trolox followed by CS in vivo.

To determine the cell-specific expression of analyzed proteins, we isolated ATII cells from lung tissue of $\mathrm{Nrf2}^{+1+}$ and $\mathrm{Nrf}^{-1-}$ mice exposed to CS in vivo (Figure 2, Panel B). We found significantly higher expressions of Nrf2, $\mathrm{HO}-1$, NQO1, GCLc and 4-HNE induced by CS in ATII cells obtained from $\mathrm{Nrf}^{+/+}$mice and lower levels of these proteins after trolox administration followed by CS. We observed enhanced expression of 53BP1, p53 and 4-HNE in ATII cells obtained from $\mathrm{Nrf}^{-1-}$ mice, and their levels were decreased by trolox administration followed by CS in vivo. Furthermore, NQO1 and GCLc expression in lung tissue and ATII cells obtained from $\mathrm{Nrf}^{+1+}$ mice exposed to $\mathrm{CS}$ and treated with trolox followed by CS in vivo correlate with Nrf2 levels. We did not detect their expression in $\mathrm{Nrf}^{-/-}$mice.

We also determined Nrf2 nuclear translocation in murine lung tissue (Supplementary Figure 1). We did not observe Nrf2 translocation in wild-type mice after treatment with trolox, which is a ROS scavenger. However, we found significant Nrf2 translocation from the cytoplasm to the nucleus in lung tissue obtained from Nrf2 ${ }^{+/+}$mice after exposure to CS, which indicates Nrf2 activation. Furthermore, this translocation was decreased after treatment with trolox followed by CS
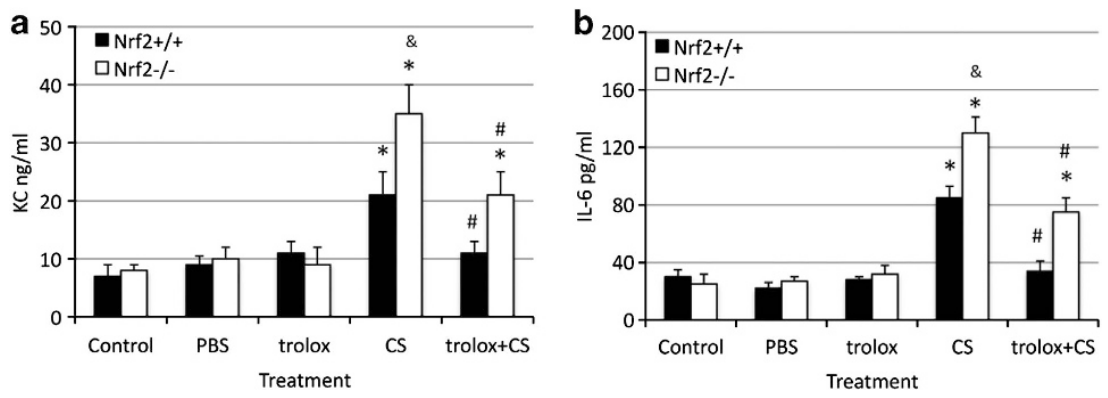

Figure 1 CS induces higher inflammation in Nrf2 ${ }^{-1-}$ mice than Nrf2 ${ }^{+1+}$ mice, which was decreased by trolox. KC (a) and IL-6 (b) levels were measured by ELISA in BAL obtained from mice treated with trolox for 5 days and exposed to CS for 4 days in vivo as described in the Materials and Methods section. *-Statistically significant increase compared with control $(P<0.05)$; \& - statistically significant increase compared with Nrf2 ${ }^{+1+}$ mice; and \#-Statistically significant decrease compared with CS alone 
A

Lung tissue
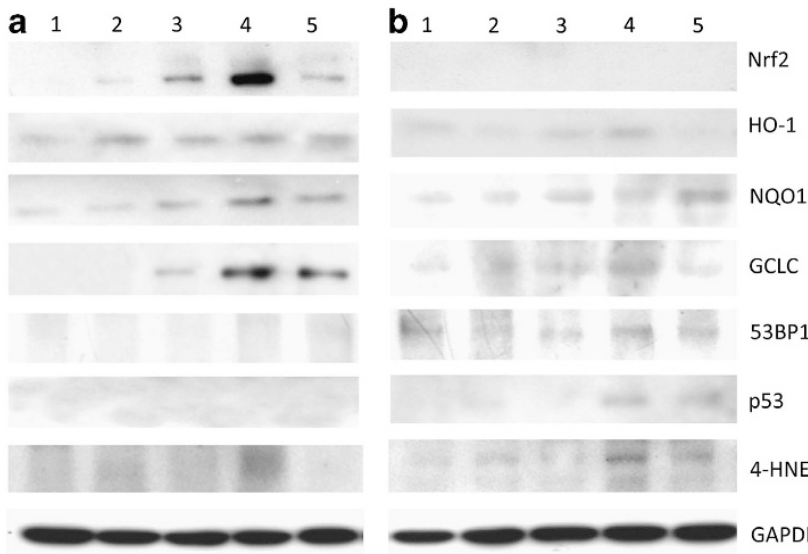

a

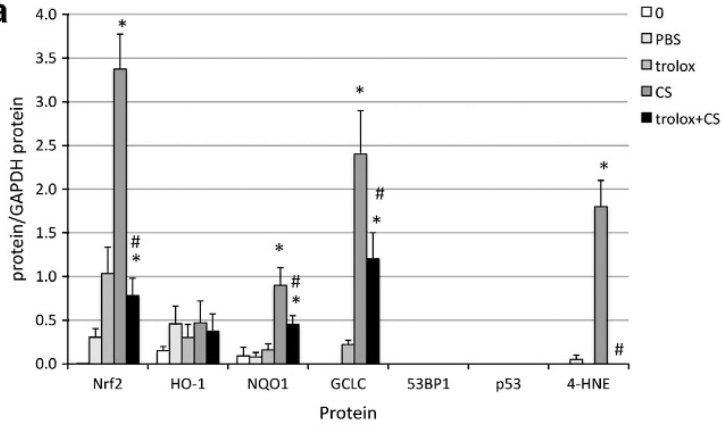

b

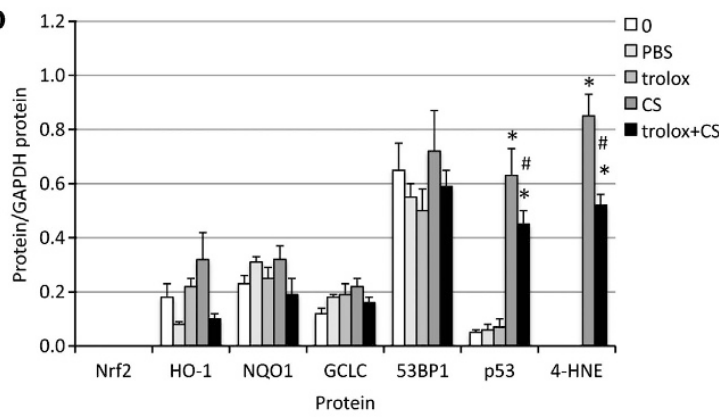

B ATII cells

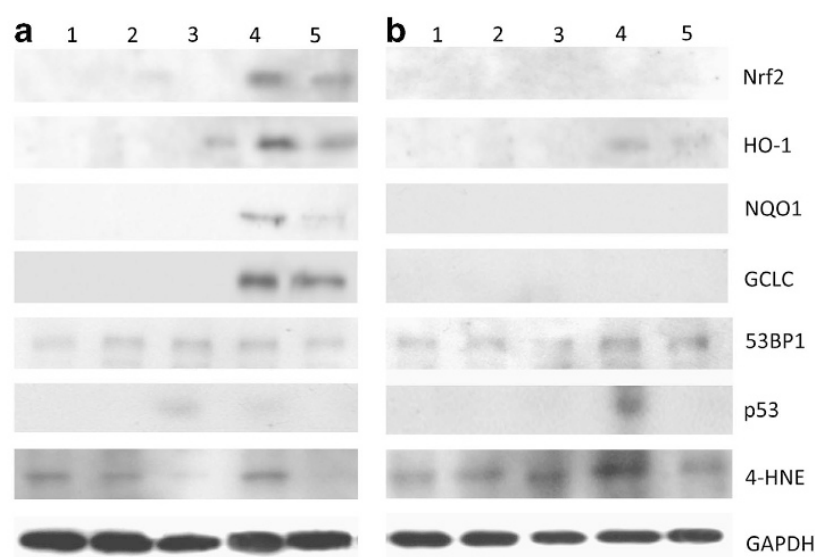

a

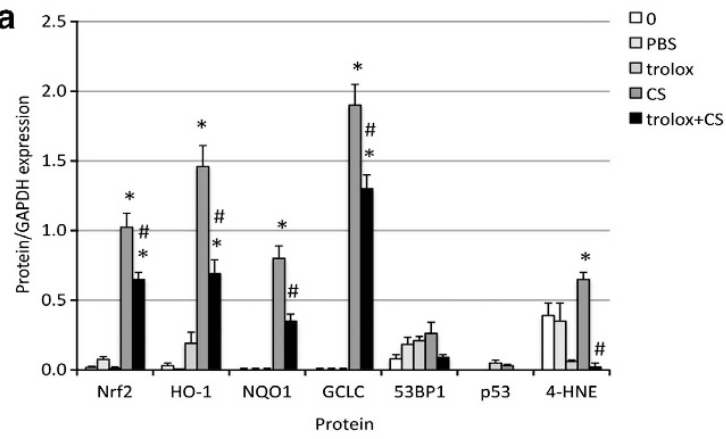

b

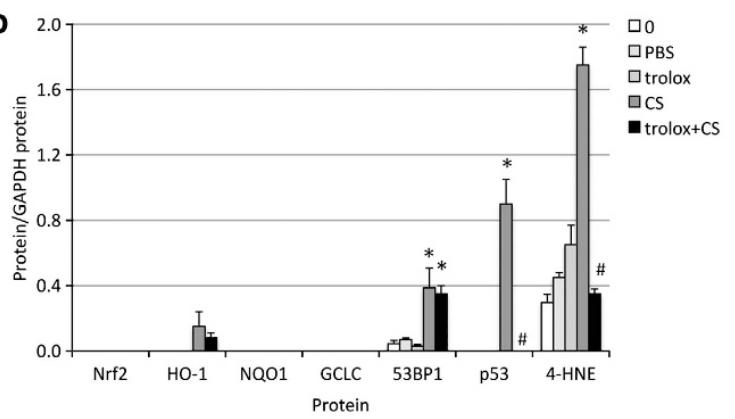

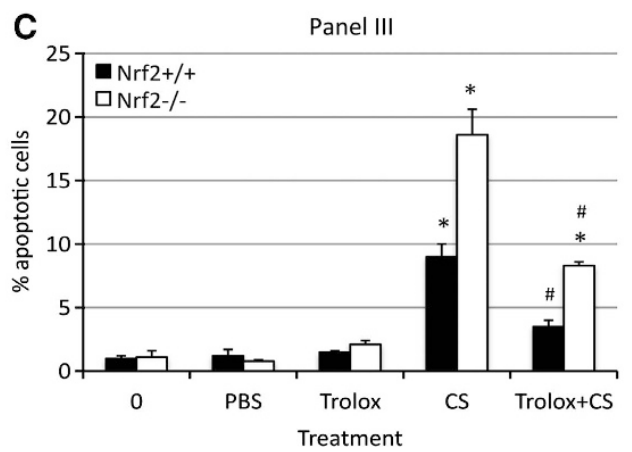

Figure 2 Trolox abolishes CS-induced injury and apoptosis in ATIl cells obtained from Nrf2 ${ }^{+1+}$ mice in vivo. Mice were treated with trolox for 5 days and exposed to CS for 4 days in vivo as described in the Materials and Methods section. Panel A-protein expression in lung tissue; Panel B-protein expression in ATII cells. a-Nrf2 ${ }^{+1+}$ mice; b-Nrf2 ${ }^{-1-}$ mice. Lane 1-control; lane 2-PBS; lane 3-trolox; lane 4-CS; lane 5-trolox + CS (immunoblotting). Relative expression of these proteins is also shown. Panel C-Paraffin-embedded lung sections were stained for proSP-C to identify ATIl cells and with fluorescein to detect apoptotic cells by TUNEL assay. ${ }^{*}$ Statistically significant difference compared with control $(P<0.05)$. \# Statistically significant decrease compared with CS alone 
exposure. This suggests a protective mechanism of trolox against oxidative stress. We did not detect Nrf2 in nuclear and cytoplasmic fractions obtained from $\mathrm{Nf} 2^{-/-}$mice.

CS also significantly increased the percentage of apoptotic ATIl cells in Nrf2 $2^{+/+}$and $\mathrm{Nrf}^{-/-}$mice in vivo (Figure 2, Panel C). We found that trolox provided partial protection for ATIl cells isolated from $\mathrm{Nrf}^{-1-}$ mice and completely abolished apoptosis induced by CS in ATII cells obtained from Nrf2 $2^{+/+}$mice. Our results indicate: (i) high susceptibility of ATII cells to injury induced by CS in vivo, (ii) higher susceptibility to DNA damage and oxidative stress of ATII cells isolated from $\mathrm{Nrf}^{-1-}$ than $\mathrm{Nrf} 2^{+/+}$mice and (iii) the protective effect of trolox and Nrf2 activation against ATII cell injury by CS in vivo.

Nrf2 activation and trolox abolishes CSE-induced murine ATII cell injury in vitro. As we observed murine ATII cell and lung injury induced by CS in vivo, we also wanted to determine the effect of CS extract (CSE)-induced ATII cell injury in vitro. We isolated and purified ATII cells from $\mathrm{Nrf}^{+/+}$and $\mathrm{Nrf}^{-1-}$ mice (Figure 3). We found that CSE induces Nrf2, $\mathrm{HO}-1$ and $\mathrm{p} 53$ expressions in $\mathrm{Nrf}^{+/+}$ mice. Furthermore, these protein levels were significantly decreased after treatment with $0.5 \mu \mathrm{M}$ trolox. We detected significantly higher expressions of 53BP1, p53 and 4-HNE in
ATII cells isolated from $\mathrm{Nrf2}^{-1-}$ mice, which were decreased after treatment with trolox.

These results are consistent with data obtained from the induction of apoptosis by CSE in murine ATII cells in vitro as measured by terminal deoxynucleotidyl transferase (TdT)-mediated dUTP nick-end labeling (TUNEL) assay (Figure 4). Apoptosis was higher in ATII cells obtained from $\mathrm{Nrf2}{ }^{-/-}$in comparison with $\mathrm{Nrf}^{+/+}$mice. Furthermore, trolox significantly decreased the percentage of apoptotic ATII cells in both genotypes. However, this antioxidant compound only partially protected ATII cells isolated from $\mathrm{Nrf2}{ }^{-1-}$ mice against injury induced by CSE in vitro and completely abolished apoptosis in these cells obtained from $\mathrm{Nrf2}^{+/+}$genotype.

We also compared inflammatory response in ATII cells isolated from $\mathrm{Nrf}^{+/+}$and $\mathrm{Nrf2} 2^{-/-}$mice after treatment with CSE in vitro (Figure 5). KC and IL-6 secretions were slightly but significantly increased by CSE only in ATII cells isolated from $\mathrm{Nrf}^{-1-}$ mice. Furthermore, treatment with trolox followed by CSE significantly decreased their levels compared with CSE alone. These results indicate higher susceptibility of ATII cells isolated from Nrf2 ${ }^{-/-}$mice to DNA damage and injury in comparison with cells obtained from $\mathrm{Nrf}^{+/+}$ mice. Furthermore, this suggests that trolox can protect ATII cells against injury presumably through ROS scavenging a
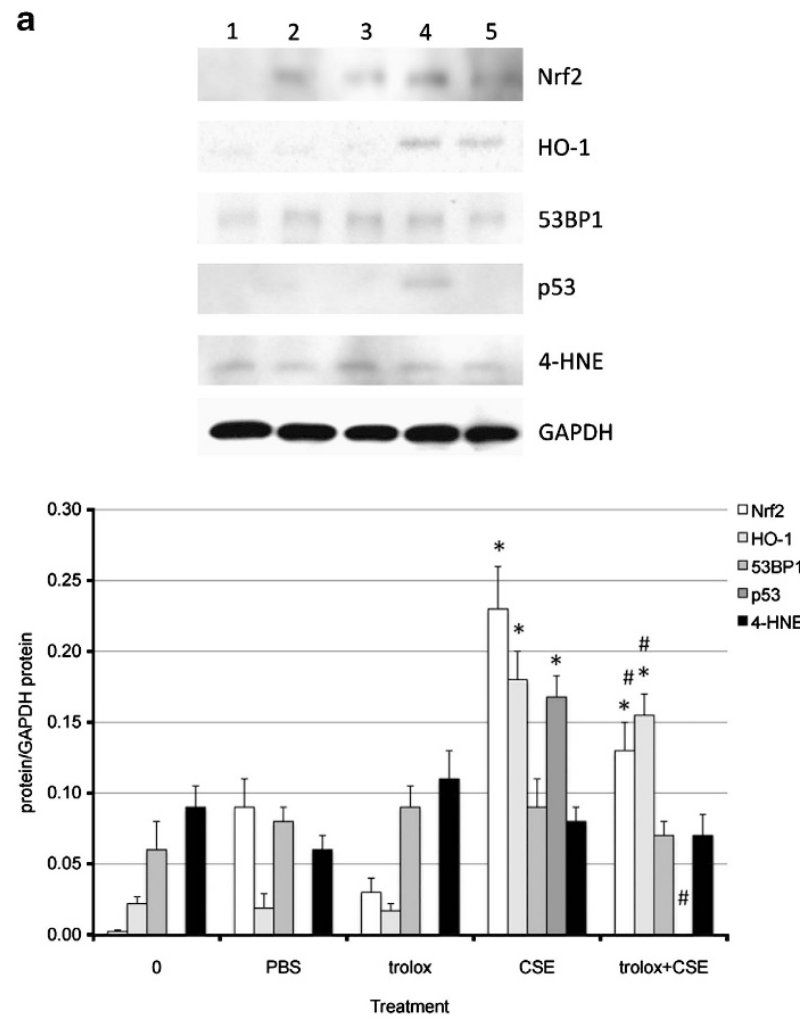

b
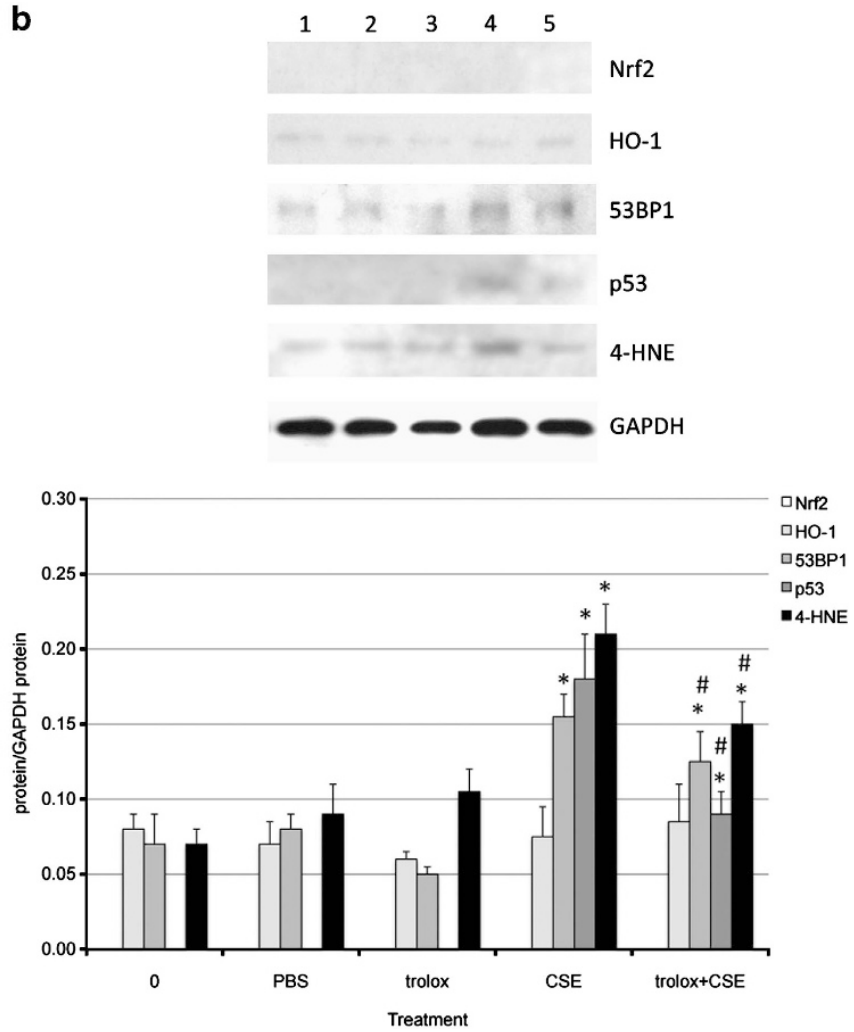

(a) and $\mathrm{Nrf}^{-1-}$ (b) mice and purified as described in lane 4-CSE; and lane 5-trolox + CSE (immunoblotting). Relative expression of these proteins is also shown. * Statistically significant increase compared with control $(P<0.05)$. "Statistically significant decrease compared with CSE alone 

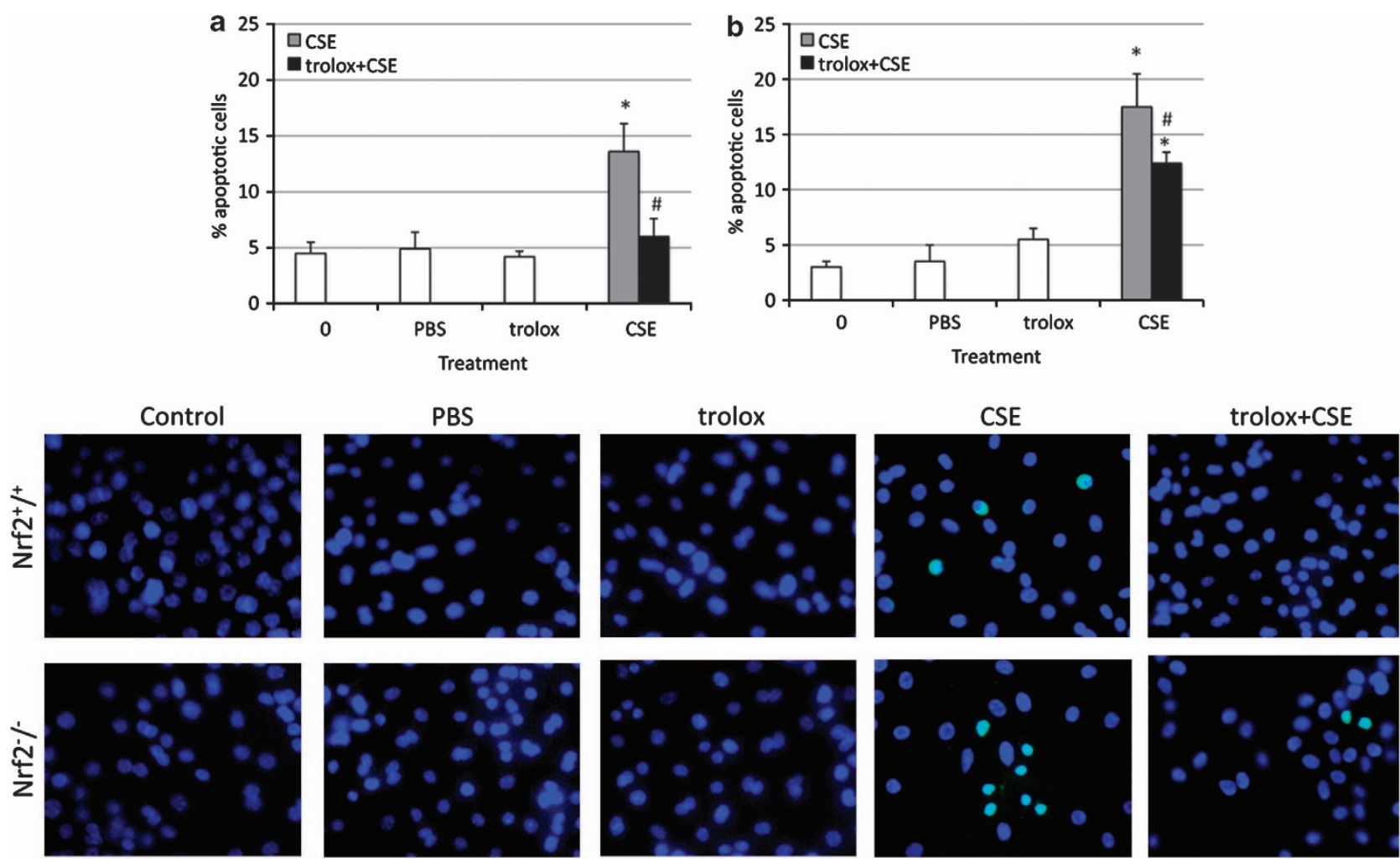

Figure 4 Trolox decreases apoptosis in murine ATII cells exposed to CSE in vitro as detected by TUNEL assay. ATII cells were isolated from Nrf2 ${ }^{+/+}\left(\right.$a) and Nrf2 ${ }^{-/-}$ (b) mice, treated with 0.5 trolox for $24 \mathrm{~h}$ and exposed to $4 \%$ CSE for $24 \mathrm{~h}$. The percentage of apoptotic ATII cells is shown. * Statistically significant increase compared with control $(P<0.05)$. "Statistically significant decrease compared with CSE alone. Representative pictures of TUNEL-positive (apoptotic) ATII cells are also shown
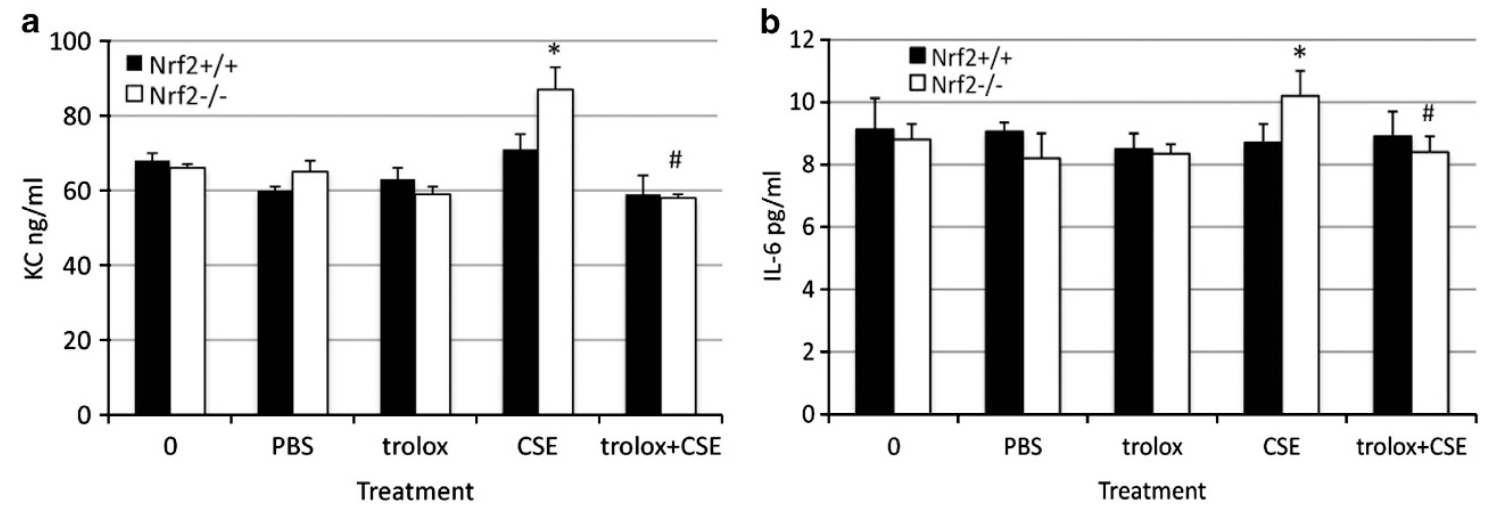

Figure 5 High inflammatory response induced by CSE in murine ATII cells obtained from Nrf2 ${ }^{-1}$ mice in vitro. KC (a) and IL-6 (b) levels in the ATII cell media were detected by ELISA. These cells were obtained from Nrf2 ${ }^{-1-}$ than $\mathrm{Nrf2}^{+/+}$mice, cultured and treated with $4 \% \mathrm{CSE}$ for $24 \mathrm{~h} .0 .5 \mu \mathrm{M}$ trolox decreases inflammatory response induced by CSE. * Statistically significant increase compared with control $(P<0.05)$. "Statistically significant decrease compared with CSE alone

activity, which can partially compensate the lack of antioxidant system regulated by Nrf2.

Trolox decreases human ATII cell injury induced by CSE in vitro. We isolated human ATII cells from lung donors to validate data obtained from murine ATII cells treated with CS both in vitro and in vivo. We found that trolox significantly decreased ROS generated by CSE in ATII cells in vitro as measured by Amplex Red Hydrogen Peroxide Assay (Figure 6, Panel A). These results indicate the protective role of trolox against ATII cell injury through ROS scavenging mechanism. We also found that treatment with trolox followed by CSE significantly decreased Nrf2, HO-1, p53, 53BP1 and 4-HNE expressions compared with CSE alone (Figure 6, Panel B).

The critical role of CSE on the mechanism of ATII cell injury was determined by p53 and Nrf2 DNA-binding activity using Transcription Factor Activation Array (Figure 6, Panel C). We found that ATII cell treatment with CSE in vitro leads to p53 and Nrf2 activation. Furthermore, treatment with trolox 
A

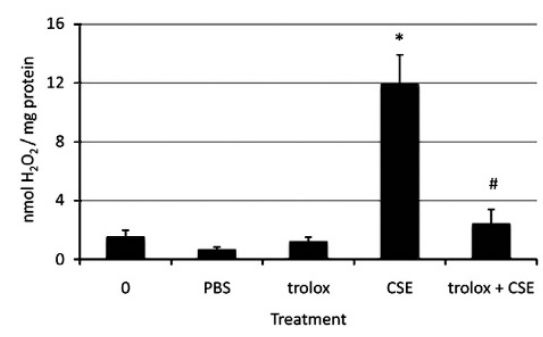

C

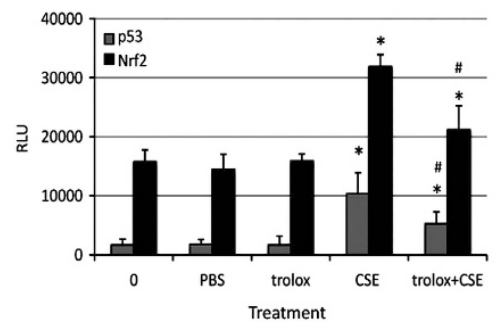

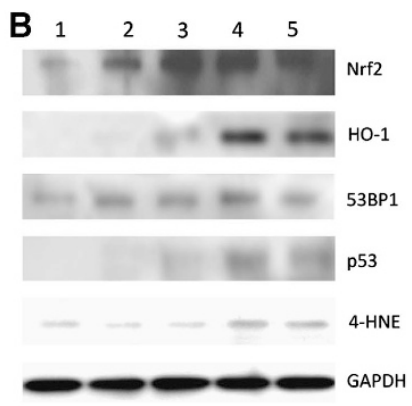

D

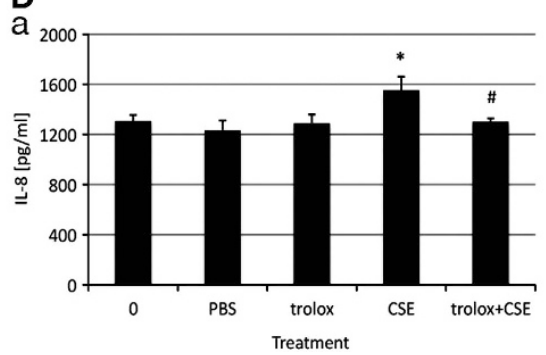

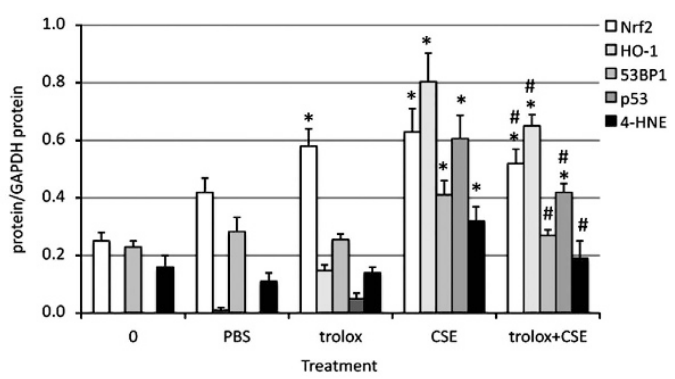

b

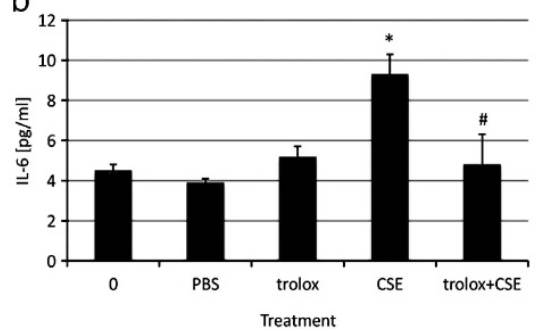

Figure 6 Trolox decreases ROS generation, injury and inflammation in human primary ATII cells in vitro induced by CSE. Human ATII cells were treated with $10 \mu \mathrm{M}$ trolox for $24 \mathrm{~h}$ followed by $6 \%$ CSE for $24 \mathrm{~h}$. Panel A-ROS generation was decreased in ATIl cells treated with trolox and CSE in comparison with CSE alone as measured by Amplex Red Hydrogen Peroxide Assay. Panel B-protein expression (immunoblotting): lane 1—control; lane 2-PBS; lane 3—trolox; lane 4-CSE; lane 5-trolox + CSE. Relative expression of these proteins is also shown. Panel C-CSE increases p53 and Nrf2 DNA-binding activity as determined by Transcription Factor Activation Array $(P<0.05)$. RLU, relative light units. Panel D-IL-8 (a) and IL-6 (b) levels in ATIl cell media as measured by ELISA. * Statistically significant increase compared with control $(P<0.05)$. \# Statistically significant decrease compared with CSE alone

followed by exposure to CSE significantly decreased p53 and Nrf2 DNA-binding activity compared with CSE alone. This suggests a protective role of trolox against DNA damage and oxidative stress. These results are consistent with our immunoblotting data.

We also determined the inflammatory response in human ATII cells treated with trolox followed by CSE in vitro (Figure 6, Panel D). We found that trolox significantly decreased IL-8 and IL-6 levels induced by CSE as measured by ELISA. Our results indicate human ATII cell injury by CSE through ROS generation, oxidative stress, DNA damage and inflammatory response. These data are in agreement with our results obtained from murine ATII cells treated with trolox and CS both in vitro and in vivo.

CS induces inflammation in ATII cells isolated from smoker lung donors ex vivo. We observed higher inflammatory response induced by CS in murine ATII cells both in vitro and in vivo and in human ATII cells in vitro. Therefore, we wanted to determine the levels of IL- 8 and IL-6 in ATII cells in smokers ex vivo. As a novel approach, we analyzed their levels in freshly isolated primary ATII cells obtained from smoker lung donors (Figure 7, Panel A). We observed significantly higher IL-8 and IL-6 levels in these cells compared with ATII cells isolated from non-smoker lung donors. We also found high p53 mRNA expression in ATII cells obtained from smokers ex vivo (Figure 7, Panel B). These results indicate the susceptibility of human ATII cells to injury and DNA damage induced by CS ex vivo and are in agreement with our in vitro and in vivo data.

\section{Discussion}

Cells respond to the accumulation of ROS generated by CS in two ways. The first one is focused on the antioxidant scavenging system through activation of Nrf2. While with the second, the cells respond to ROS-induced DNA damage through p53-mediated apoptosis in the case of unrepairable DNA damage. ${ }^{27}$ In this study, we addressed these two responses in human and murine primary ATII cells exposed to $\mathrm{CS}$ in vitro, in vivo and ex vivo. We confirmed our hypothesis that Nrf2 activation is important to protect ATII cells against injury by CS. Furthermore, the antioxidant compound trolox decreased DNA damage and the inflammation process in ATII cells induced by CS through ROS scavenging mechanism. We show for the first time that trolox partially provides protection against ATII cell injury in the absence of Nrf2.

We found higher KC and IL-6 levels in BAL obtained from $\mathrm{Nrf} 2^{-1-}$ mice than from Nrf2 $2^{+1+}$ mice exposed to CS in vivo. The discrepancy between the increase in Nrf2 not accompanied by an increase of $\mathrm{HO}-1$ in lung tissue obtained from wild-type mice exposed to CS in vivo can be explained in three ways. First, it has been reported that $\mathrm{HO}-1$ activation by $\mathrm{Nrf} 2$ represents a late event in the antioxidant response. ${ }^{28}$ Second, we used a low CS concentration $\left(70 \mathrm{mg} / \mathrm{m}^{3}\right)$ due to lethality in $\mathrm{Nrf} 2^{-1-}$ mice. HO-1 induction has been reported for wild-type mice when CS was used at much higher concentrations (up to $\left.250 \mathrm{mg} / \mathrm{m}^{3}\right) .{ }^{29}$ Third, we observed HO-1 induction in ATII cells but not in the lung tissue obtained from $\mathrm{Nrf2}^{+/+}$mice after exposure to CS in vivo. This suggests high ATII cell sensitivity to oxidative stress. 


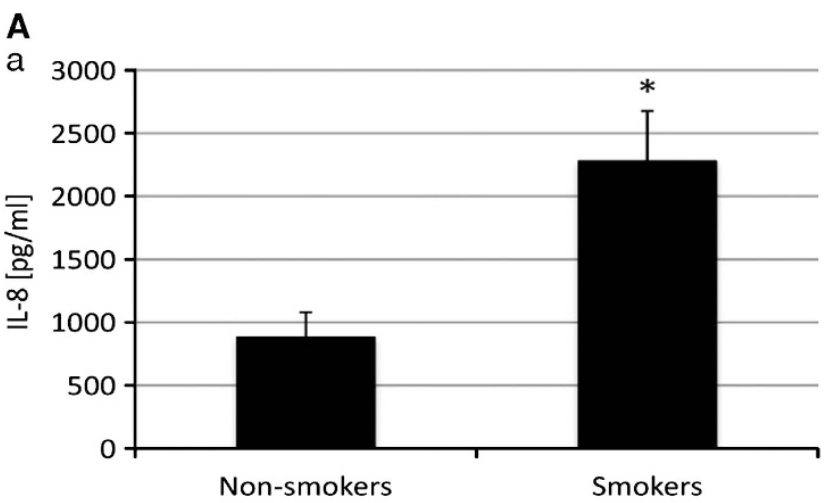

Groups

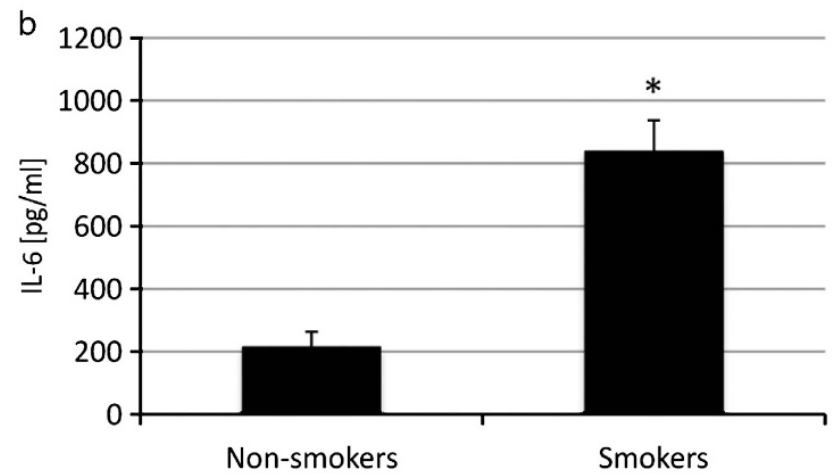

Groups

B

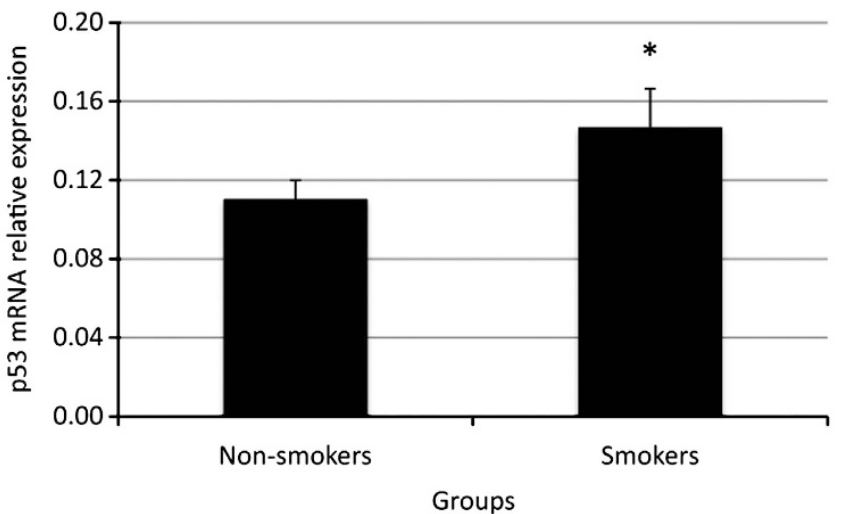

Figure 7 CS increases IL-8 and IL-6 levels in human primary ATII cells. Panel A-higher IL-8 (a) and IL-6 (b) levels in whole ATII cell extracts obtained from smoker in comparison with non-smoker lung donors as measured by ELISA. Panel B-smoking induces p53 mRNA expression in ATII cells isolated from smoker lung donors compared with non-smoker lung donors as measured by RT-PCR. ${ }^{*}$ Statistically significant difference compared with non-smokers $(P<0.05)$

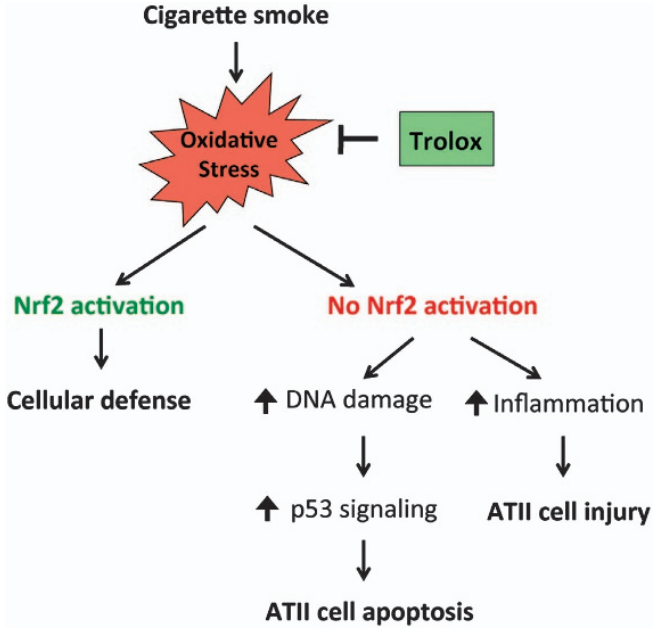

Figure 8 Trolox contributes to Nrf2-mediated protection of ATII cells from apoptosis, injury and inflammation induced by CS. CS generates oxidative stress, which is decreased by trolox and the activation of Nrf2. Lack of Nrf2 and this antioxidant compound leads to accumulation of ROS, induction of DNA damage, inflammation and p53-dependent apoptosis in ATII cells

We also found that CS induces nuclear Nrf2 translocation in vivo, which indicates its activation. We did not observe this translocation after trolox administration, which was also reported in vitro. ${ }^{30} \mathrm{Nrf2}$ nuclear translocation was decreased after treatment with trolox followed by CS in comparison with CS alone, which suggests cytoprotective role of this antioxidant compound. These observations are in agreement with our previous studies in human alveolar type I-like cells treated with trolox followed by exposure to CSE in vitro. ${ }^{31}$

Furthermore, ATII cells isolated from $\mathrm{Nrf}^{-1-}$ mice were more susceptible to injury by CS both in vivo and in vitro. Sussan et al. $^{32}$ reported lung injury in $\mathrm{Nrf2}^{-1-}$ mice by CS. However, to our knowledge, there are no data on in vivo and in vitro comparison in murine primary ATII cells with trolox supplementation. Chen et al. ${ }^{33}$ reported that CSE induced apoptosis in mouse embryonic lung cells in vitro as detected by comet assay. The involvement of p53 in the regulation of the redox homeostasis has been reported. ${ }^{34}$ High levels of p53 appear to be associated with the decrease of antioxidant defense and with the consequent increase of intracellular ROS. ${ }^{27}$ On the contrary, it was suggested that DNA damagedependent activation of p53 also induces a significant accumulation of ROS followed by the induction of p53dependent apoptosis. ${ }^{35}$ Our findings indicate the protective role of Nrf2 against the inflammatory process, oxidative stress-induced DNA damage and p53-dependent apoptosis induction by CS in murine ATII cells both in vivo and in vitro. 53BP1 is required for an appropriate cellular response to DNA damage; however, its function is not fully understood. ${ }^{4}$ 
We observed higher 53BP1 levels in ATII cells obtained from $\mathrm{Nrf}^{-1-}$ mice than $\mathrm{Nrf2} 2^{+1+}$ mice exposed to CS. This suggests that $53 \mathrm{BP} 1$ is associated with CS, which reflects oxidative DNA damage due to the lack of the antioxidant defense system regulated by Nrf2.

Higher expressions of 53BP1 and p53 observed in murine lung tissue and ATII cells obtained from $\mathrm{Nrf}^{-1-}$ mice compared with $\mathrm{Nrf} 2^{+/+}$mice after exposure to CS in vivo or in vitro can be explained in two ways. First, these cells have higher susceptibility to DNA damage mediated by p53/53BP1 owing to the lack of antioxidant defense system. It has been recently reported that in murine embryonic fibroblasts obtained from Nrf2 $2^{-1-}$ mice, Mdm2 expression (p53 inhibitor) was repressed and p53 protein was highly accumulated compared with wild-type cells. ${ }^{36}$ Furthermore, cells with Nrf2 knockdown had a higher level of DNA strand breaks induced by nickel in vitro. ${ }^{37}$ Second, there is a cross-talk between Nrf2 and $553 .^{38}$ Functional Nrf2 can induce antioxidant defense systems to prevent oxidative damage and p53 activation. This hypothesis can be also confirmed by the higher binding activity of Nrf2 than p53 after ATII cell exposure to CSE in vitro as detected by transcription factor DNA-binding activities (Figure 6). Further studies are required to complete our knowledge of the dominance or co-existence of these two pathways. Our results indicate that ATII cells isolated from $\mathrm{Nrf2} 2^{-1-}$ mice and exposed to CS will require p53 activation: (i) to induce a compensatory increase in antioxidant proteins, which can counteract ROS attack on DNA, (ii) to repair DNA damage and/or (iii) to induce apoptosis for the prevention of conversion of acquired mutations to inherited mutations. ${ }^{36}$

We also analyzed the effect of supplementation with trolox, a ROS scavenger, against murine ATII cell injury followed by exposure to CS both in vivo and in vitro. This compound was able to ameliorate oxidative stress induced by CS as measured by 4-HNE levels. We also found that trolox significantly decreased $\mathrm{KC}$ and IL-6 levels, 53BP1 and p53 expression, and the percentage of ATII apoptotic cells induced by CS. It is worthwhile to note that this compound partially rescued ATII cells obtained from the $\mathrm{Nrf}^{-1-}$ from injury. These findings implicate that ROS accumulation is an effector in each case and that DNA damage is of oxidative origin. Simbula et al. ${ }^{39}$ reported the protective role of trolox against p53-dependent cell apoptosis through a ROS scavenging mechanism in hepatoma cells. Our results are also in agreement with Chen et al., ${ }^{33}$ who found that vitamin $\mathrm{E}$ significantly decreased DNA strand breaks induced by CSE in mouse embryonic lung cells in vitro. Other reports showed the protective effect of vitamin $E$ against DNA oxidation, decreased formation of 7,8-dihydro-8-oxo-2'-deoxyguanosine,${ }^{40}$ lipid peroxidation, ${ }^{41}$ single DNA strand breaks ${ }^{42}$ and DNA adduct (benzo $(\alpha)$ pyrene-DNA) formation ${ }^{43}$ induced by $\mathrm{CS}$ in different tissue in vivo. Furthermore, acute lung inflammation and dysfunction induced by CS in vivo was decreased after vitamin E administration. ${ }^{44}$

We used human primary ATII cells in vitro and ex vivo to validate our results obtained from murine ATII cells exposed to CS both in vitro and in vivo. We found higher IL-8, IL-6 and p53 mRNA levels in ATII cells obtained from smoker lung donors in comparison with non-smokers. This indicates the inflammatory and genotoxic effects of CS on ATII cells ex vivo.
Furthermore, these results indicate increased ATII cell injury, likely due to an impaired antioxidant defense system beyond the threshold of Nrf2 activity. Moreover, we also treated human ATII cells with trolox followed by exposure to CSE in vitro. We found that trolox decreased ROS generation, Nrf2, p53, 53BP1 and HO-1 expressions, and IL-8 and IL- 6 levels induced by CSE. We have recently shown that trolox also protected human primary alveolar type I-like cells against injury induced by CSE in vitro. ${ }^{31}$. Moreover, Nardini et al. ${ }^{45}$ also showed that supplementation of human bronchial epithelial cells HBE1 with vitamin E strongly prevented acrolein-induced generation of intracellular oxidants. They concluded that the oxidative stress following acrolein exposure seems to be an important event triggering the apoptotic response in this model system. Furthermore, there are several clinical trials, which reported the importance of vitamin $E$ against CS-induced lung injury. Intake of vitamin E was associated with reduced oxidant levels in current smoker COPD patients. ${ }^{46} \mathrm{Wu}$ et al. ${ }^{47}$ also showed a reduction in oxidativeinduced DNA damage of white blood cells in the vitamin E-supplemented group versus the placebo group after a 12week supplementation period in COPD patients. Furthermore, assignment to vitamin $\mathrm{E}$ in healthy women led to a reduction in the risk of new chronic lung disease where CS was a strong predictor. $^{23}$

In summary, our results indicate the susceptibility of murine and human ATII cells to injury by CS. Trolox can protect against oxidative stress, genotoxicity and inflammation induced by CS through a ROS scavenging mechanism (Figure 8). Further studies of the integration of Nrf2 and p53 signaling would be important to determine the cell fate in response to oxidative stress induced by CS and antioxidant prevention strategies in CS-related lung diseases.

\begin{abstract}
Materials and Methods
Animals. We used wild-type C57BL/6 mice (The Jackson Laboratory, Bar Harbor, ME, USA) and Nrf2 ${ }^{-1-}$ mice (C57BL/6 background, developed by Dr. M Yamamoto ${ }^{48}$ and kindly provided by Steven Kleeberger, NIH/NIEHS). Mouse colonies were maintained at National Jewish Health. All mice were fed ad libitum and housed in an Institutional Animal Care and Use Committee (IACUC)accredited facility in HEPA-filtered cages. Animal care, handling and experimental procedures were carried out in accordance with a protocol approved by the IACUC of National Jewish Health. At 4 weeks of age, mice were fed an AIN-76A diet for 10 days $^{49}$ before in vitro or in vivo experiments.
\end{abstract}

Nuclear and cytoplasmic fraction isolation. Lungs were harvested to isolate nuclear and cytoplasmic fractions for subsequequent western blotting using the NE-PER Nuclear and Cytoplasmic Extraction Reagents (Thermo Scientific, Rockford, IL, USA) according to the manufacturer's recommendations. Briefly, tissue was homogenized in $10 \mu \mathrm{l} / \mathrm{mg}$ CER I buffer with a GentleMACS dissociator (Miltenyi Biotec Inc., Auburn, CA, USA). After that buffer CER II was added, the lysate was spun down and the supernatant was collected as the cytoplasmic fraction. The pellet was resuspended in buffer NER and vortexed for $15 \mathrm{~s}$ every $10 \mathrm{~min}$ for a total of $40 \mathrm{~min}$. The lysate was spun down for $10 \mathrm{~min}$ at $20000 \times \mathrm{g}$ and the supernatant was collected as the nuclear fraction. We used lamin-B1 and IKB- $\alpha$, as markers of nuclear and cytoplasmic fractions, respectively, as previously reported. ${ }^{50}$

Murine ATIl cell isolation and culture. Nrf2 ${ }^{+1+}$ and $\mathrm{Nrf2}{ }^{-1-}$ mice were euthanized, and BAL fluid was obtained through a tracheal cannula as previously described. ${ }^{51}$ Mice were killed and lungs were perfused with PBS via the pulmonary artery. 
ATII cells were isolated as we previously described. ${ }^{26}$ The trachea was exposed and cannulated, and dispase (BD Biosciences, Heidelberg, Germany) was instilled into the lung followed by low melting point agarose (International Biotechnologies Inc., New Haven, CT, USA) for 2 min. Lungs were then dissected, placed in a tube containing dispase for 5 min at $37^{\circ} \mathrm{C}$ and tissue was gently minced by GentleMACS Dissociator (Miltenyi Biotec Inc.). Unique to other studies, ATII cells were purified using CD45-negative depletion (CD45 MicroBeads; Miltenyi Biotec Inc.) and biotinylated anti-mouse Ep-CAM (e-Bioscience, San Diego, CA, USA) with Streptavidin MicroBeads (Miltenyi Biotec Inc.) for a positive selection. The purity of these cells as measured by flow cytometry using cytokeratin, and SP-A was $>90 \%$ (data not shown). ${ }^{26}$ Murine ATIl cells were cultured as we previously described ${ }^{26}$ Briefly, they were plated for 1 day in DMEM with $5 \%$ rat serum with $20 \mathrm{mM}$ HEPES on millicell inserts coated with a mixture of $20 \%$ Engelbreth-HolmSwarm tumor matrix (BD Biosciences) and $80 \%$ rat-tail collagen in DMEM and then cultured for 3 days with $1 \%$ CS-stripped FBS along with $10 \mathrm{ng} / \mathrm{ml}$ keratinocyte growth factor (R\&D Systems Inc., Minneapolis, MN, USA).

Isolation and culture of human ATII cells. We obtained deidentified human lungs not suitable for transplantation and donated for medical research from the National Disease Research Interchange (Philadelphia, PA, USA) and the International Institute for the Advancement of Medicine (Edison, NJ, USA). We selected donors without a history of chronic lung disease and with reasonable lung function with a $\mathrm{PaO}_{2} / \mathrm{FIO}_{2}$ ratio of $>225$, a clinical history and X-ray that did not indicate infection, and limited time on a ventilator. We analyzed the age, gender, race, smoking history, cause of death, medical history and medications at the time of death. Smokers were individuals who smoked 10-25 cigarettes per day for at least 3 years, while non-smokers included those who had never smoked. The Committee for the Protection of Human Subjects at National Jewish Health approved this research.

The human ATII cell isolation method has been published previously. ${ }^{52}$ Briefly, the right middle lobe was perfused and lavaged, and then instilled with elastase (12.9 U/ml; Roche Diagnostics, Indianapolis, IN, USA) for $50 \mathrm{~min}$ at $37^{\circ} \mathrm{C}$. The lung was minced and subsequently the cells were filtrated and purified by centrifugation with densities of 1.080 and 1.040 on a density gradient made of Optiprep (Accurate Chemical Scientific Corp., Westbury, NY, USA) and by negative selection with CD14-coated magnetic beads (Dynal Biotech ASA, Oslo, Norway) and binding to IgG-coated (Sigma Chemicals Inc., St. Louis, MO, USA) dishes. The purity of ATII cells analyzed by staining for cytokeratin CAM 5.2 (Dako, Carpinteria, CA, USA) was $\sim 80 \%$ before plating and over $95 \%$ after adherence in culture. ${ }^{53}$

Exposure to trolox and CS in vivo. Five-week-old mice were exposed to CS from Kentucky reference cigarette 3R4F (University of Kentucky) for $5 \mathrm{~h}$ per day for 4 days using a Teague TE-10 smoking system (Teague Enterprises, Woodland, CA, USA). The average particulate matter was $70 \mathrm{mg} / \mathrm{m}^{3}$ and carbon monoxide levels were <300 p.p.m. The antioxidant, trolox (CAS 53188-07-1; Calbiochem-EMD Biosciences Inc., La Jolla, CA, USA), was dissolved in PBS. In some experiments, mice received $35 \mathrm{mg} / \mathrm{kg}$ body weight trolo ${ }^{54}$ in PBS by oral gavage every $24 \mathrm{~h}$ starting 1 day before exposure to CS and for 4 days during exposure to CS.

Treatment with trolox and CSE in vitro. The CSE was prepared as we previously described. ${ }^{31}$ Briefly, the smoke of one $3 \mathrm{R} 4 \mathrm{~F}$ cigarette without filter (Kentucky Tobacco Research and Development Center, Lexington, KY, USA) containing $9.5 \mathrm{mg}$ tar and $0.72 \mathrm{mg}$ nicotine was drawn into $12.5 \mathrm{ml}$ DMEM with a peristaltic pump (Manostat 72-310-000; Barnant Company, Barrington, IL, USA). The pump was set at an optimum speed to allow one cigarette to burn in $15 \mathrm{~min}$ and resulting solution was considered $100 \%$ CSE. This solution was filtered and applied immediately to the murine (4\%) and human (6\%) ATII cell cultures for $24 \mathrm{~h}$. In some experiments, ATII cells were treated with trolox for $24 \mathrm{~h}$ before exposure to CSE. Trolox concentration used in murine $(0.5 \mu \mathrm{M})$ and human $(10 \mu \mathrm{M})$ ATII cells in vitro was selected based on the viability assay using trypan blue staining and MTT assay (data not shown).

TUNEL assay. We analyzed the apoptosis of murine and human ATII cells using a combination of staining for anti-prosurfactant protein $C$ (proSP-C Chemicon, San Diego, CA, USA) and TUNEL (Promega, Madison, WI, USA) assay as previously described with slight modifications. ${ }^{55-57}$ Briefly, ATII cells were fixed in $4 \%$ paraformaldehyde (Electron Microscopy Sciences, Hatfield, PA, USA) in PBS and permeabilized with $0.2 \%$ triton X-100 (Sigma Chemicals Inc.).
Then slides with cells were incubated for $1 \mathrm{~h}$ at $37^{\circ} \mathrm{C}$ in a humid chamber in the presence of TdT. In the negative control, no TdT was added whereas in the positive control $10 \mathrm{U} / \mathrm{ml}$ DNase (Promega) was used (data not shown), respectively, according to manufacturer's recommendations. Cells were then blocked with a 1:1 mix of Superblock Blocking Buffer (Pierce, Rockford, IL, USA) and $3 \%$ normal donkey serum, and incubated with anti-proSP-C (Abcam, Cambridge, MA, USA, Ab-3786) for $1 \mathrm{~h}$. Anti-rabbit secondary Alexa-Fluor 594 (Invitrogen Corp., Carlsband, CA, USA) was added to slides and incubated for $30 \mathrm{~min}$. Cells were mounted with Vectashield medium containing DAPI (Vector Laboratories, Burlingame, CA, USA) and analyzed by fluorescence microscopy (Zeiss Axioskop 2, Thornwood, NY, USA). The percentage of TUNEL-positive apoptotic ATII cells labeled with fluorescein (fluorescein-dUTP-labeled DNA) was calculated per 10 high-power fields (magnification $10 \times 40$ )..$^{58}$

ELISA. IL-8, KC and IL-6 were measured by ELISA (ELISA Tech., Aurora, CO, USA) in the murine BAL, murine and human ATII cell culture supernatant or in extracts of freshly isolated human ATII cells. We followed the manufacturer's recommendations using a MicroQuant microplate spectrophotometer (BioTek Instruments, Winooski, VT, USA) and data were analyzed with KCjunior Data Analysis Software (Biotek Instruments, Winooski, VT, USA).

Western blotting. Expression of proteins from ATII cells or lung tissue were measured by western blotting as we described previously. ${ }^{52}$ Briefly, polyacrylamide gradient gels (8-16\%; Invitrogen Corp.) were run in tris glycine buffer to separate the proteins. Protein loading was normalized to mouse antiglyceraldehyde-3-phosphate dehydrogenase (anti-GAPDH) purchased from Abcam. Mouse anti-HO-1 was purchased from Assay Designs (Ann Arbor, MI, USA), rabbit anti-Nrf2, anti-p53, anti-NQ01, lamin-B1 and anti-IKB- $\alpha$ were purchased from Santa Cruz Biotechnology (Santa Cruz, CA, USA), rabbit anti-53BP1, rabbit anti-4-HNE and rabbit anti-GCLC from Abcam. Horseradish peroxidase (HRP)-conjugated AffiniPure donkey anti-rabbit $\lg G$ and HRP-conjugated AffiniPure donkey anti-mouse IgG were purchased from Jackson ImmunoResearch (West Grove, PA, USA). The blots were then developed using an enhanced chemiluminesence western blotting kit according to the manufacturer's instructions (Amersham Pharmacia Biotech, Piscataway, NJ, USA). Images were quantitated using NIH Image 1.62 software (Bethesda, MD, USA).

ROS production. We compared ROS production in human ATII cells treated with $10 \mu \mathrm{M}$ trolox followed by $6 \%$ CSE in vitro. We used the Amplex Red Hydrogen Peroxide Assay (Invitrogen Corp.) as a quantititative index of ROS generation. ${ }^{59,60}$ Hydrogen peroxide is one of the most stable forms of ROS, therefore this method allows observation of oxidation processes in real time. Amplex Red reacts with hydrogen peroxide in the presence of HRP with a 1:1 stoichiometry to form resorufin. Briefly, $50 \mu \mathrm{l}$ of samples and standards were mixed with $50 \mu \mathrm{l}$ of $100 \mu \mathrm{M}$ Amplex Red and $0.2 \mathrm{U} / \mathrm{ml} \mathrm{HRP} \mathrm{solution,} \mathrm{and} \mathrm{incubated}$ for $30 \mathrm{~min}$. Absorbance was measured at $560 \mathrm{~nm}$ (SpectraMax340PC, Molecular Devices, Sunnyvale, CA, USA) and calculated concentrations were normalized to protein content.

Transcription Factor Activation. Transcription factor DNA-binding activities were measured using Transcription Factor Activation Profiling Plate Array II (Signosis, Sunnyvale, CA, USA) in nuclear extracts prepared from human ATII cells according to manufacturer's recommendations. Briefly, biotin-labeled probes were mixed with these extracts to allow formation of transcription factorDNA complexes for $30 \mathrm{~min}$ at $16^{\circ} \mathrm{C}$. After elution of bound probe, a hybridization plate was used for quantitative analysis. The captured transcription factor probe was detected with streptavidin-HRP conjugate and measured as relative light units on a microplate luminometer (SpectraMax340PC, Molecular Devices).

Real-time qPCR. Total RNA was isolated from human ATIl cells using the RNeasy Mini kit (Qiagen, Germantown, MD, USA) according to the manufacturers' recommendations. Assay on-demand p53 probe (Hs99999147_m1) was purchased from Life Technologies (Grand Island, NY, USA). Before reverse transcription, isolated RNA was assessed for quantity and quality with a Nanodrop 1000 spectrophotometer, and $0.5 \mu \mathrm{g}$ of RNA was used to synthesize cDNA using qScript cDNA Supermix (Quanta Biosciences, Gaithersburg, MD, USA) in a total sample volume of $30 \mu \mathrm{l}$. The cycling conditions for RT-PCR were as follows: $25^{\circ} \mathrm{C}$ for $5 \mathrm{~min}, 42^{\circ} \mathrm{C}$ for $30 \mathrm{~min}$ and $85^{\circ} \mathrm{C}$ for $5 \mathrm{~min}$. Taqman Gene Expression Master Mix (Life Technologies) was then used for qPCR with a total sample volume of 
$15 \mu \mathrm{l}$. Before use, hydrolysis probes were tested for efficiency and optimal annealing temperature. Gene expression levels were calculated as a ratio of the p53 probe to the expression of the reference gene, GAPDH (Hs99999915_m1, Life Technologies) using the C1000 Thermocycler (Bio-Rad, Hercules, CA, USA). Cycling conditions were $50^{\circ} \mathrm{C}$ for $2 \mathrm{~min}, 95^{\circ} \mathrm{C}$ for $10 \mathrm{~min}$ and then 39 cycles of amplification at $95^{\circ} \mathrm{C}$ for $15 \mathrm{~s}, 60^{\circ} \mathrm{C}$ for $1 \mathrm{~min}$. Data were analyzed using the $\Delta \Delta \mathrm{Ct}$ method.

Statistical analysis. One-way ANOVA by GraphPad Prism 4 (La Jolla, CA, USA) was used. A Dunnett's test was applied $(P<0.05)$. Data are shown here as the mean \pm S.E.M. from at least three independent experiments.

\section{Conflict of Interest}

The authors declare no conflict of interest.

Acknowledgements. We thank Robert $J$ Mason for helpful suggestions and critical reading of this manuscript. We would like to thank Steven $\mathrm{R}$ Kleeberger (NIH/NIEHS) for providing Nrf2 ${ }^{-1-}$ mice for this study. We also thank Erika K Ross and Karen E Edeen for help with murine ATII cell isolation, and Yoko Ito, Karen E Edeen, Emily A Travanty and Jieru Wang for assistance with human ATIl cell isolations. Finally, we thank Sarah Murrell for assistance with manuscript preparation. This work was supported by Young Clinical Scientist Award from the Flight Attendant Medical Research Institute (BK), Translational Research Initiative in Personalized Healthcare, National Jewish Health (BK), Basic Science Section Grant, National Jewish Health (BK) and R01 ES016285 (RMT).

1. Barnes PJ. Mediators of chronic obstructive pulmonary disease. Pharmacol Rev 2004; 56 : 515-548.

2. Marin L, Colombo P, Bebawy M, Young PM, Traini D. Chronic obstructive pulmonary disease: patho-physiology, current methods of treatment and the potential for simvastatin in disease management. Expert Opin Drug Deliv 2011; 8: 1205-1220.

3. van der Toorn M, Slebos DJ, de Bruin HG, Leuvenink HG, Bakker SJ, Gans RO et al. Cigarette smoke-induced blockade of the mitochondrial respiratory chain switches lung epithelial cell apoptosis into necrosis. Am J Physiol Lung Cell Mol Physiol 2007; 292: L1211-L1218.

4. Ward IM, Minn K, van Deursen J, Chen J. p53 Binding protein 53BP1 is required for DNA damage responses and tumor suppression in mice. Mol Cell Biol 2003; 23: 2556-2563.

5. Noon AT, Goodarzi AA. 53BP1-mediated DNA double strand break repair: insert bad pun here. DNA Repair (Amst) 2011; 10: 1071-1076.

6. Lai TC, Chow KC, Lin TY, Chiang IP, Fang HY, Chen CY et al. Expression of 53BP1 as a cisplatin-resistant marker in patients with lung adenocarcinomas. Oncol Rep 2010; 24: 321-328.

7. Cho HY, Reddy SP, Kleeberger SR. Nrf2 defends the lung from oxidative stress. Antioxid Redox Signal 2006; 8: 76-87.

8. Kwak MK, Itoh K, Yamamoto M, Sutter TR, Kensler TW. Role of transcription factor Nrf2 in the induction of hepatic phase 2 and antioxidative enzymes in vivo by the cancer chemoprotective agent, 3H-1, 2-dimethiole-3-thione. Mol Med 2001; 7: 135-145.

9. Cho HY, Kleeberger SR. Nrf2 protects against airway disorders. Toxicol Appl Pharmacol 2010; 244: 43-56.

10. Boutten A, Goven D, Boczkowski J, Bonay M. Oxidative stress targets in pulmonary emphysema: focus on the Nrf2 pathway. Expert Opin Ther Targets 2010; 14: 329-346.

11. Goven D, Boutten A, Lecon-Malas V, Marchal-Somme J, Amara N, Crestani B et al. Altered Nrf2/Keap1-Bach1 equilibrium in pulmonary emphysema. Thorax 2008; 63: 916-924.

12. Donnelly LE, Barnes PJ. Expression of heme oxygenase in human airway epithelial cells. Am J Respir Cell Mol Biol 2001; 24: 295-303.

13. Gebel S, Gerstmayer B, Bosio A, Haussmann HJ, Van Miert E, Muller T. Gene expression profiling in respiratory tissues from rats exposed to mainstream cigarette smoke. Carcinogenesis 2004; 25: 169-178.

14. Nicks ME, O'Brien MM, Bowler RP. Plasma antioxidants are associated with impaired lung function and COPD exacerbations in smokers. COPD 2011; 8: 264-269.

15. Wang S, Sun NN, Zhang J, Watson RR, Witten ML. Immunomodulatory effects of high-dose alpha-tocopherol acetate on mice subjected to sidestream cigarette smoke. Toxicology 2002; 175: 235-245.

16. Sinha P, Kolleck I, Volk HD, Schlame M, Rustow B. Vitamin E deficiency sensitizes alveolar type II cells for apoptosis. Biochim Biophys Acta 2002; 1583: 91-98.

17. Bhalla DK, Hirata F, Rishi AK, Gairola CG. Cigarette smoke, inflammation, and lung injury: a mechanistic perspective. J Toxicol Environ Health B Crit Rev 2009; 12: 45-64.

18. Liu H, Ma L, Wu J, Wang K, Chen X. Apoptosis of alveolar wall cells in chronic obstructive pulmonary disease patients with pulmonary emphysema is involved in emphysematous changes. J Huazhong Univ Sci Technol Med Sci 2009; 29: 466-469.
19. Fiala ES, Sohn OS, Wang CX, Seibert E, Tsurutani J, Dennis PA et al. Induction of preneoplastic lung lesions in guinea pigs by cigarette smoke inhalation and their exacerbation by high dietary levels of vitamins $C$ and $\mathrm{E}$. Carcinogenesis 2005; 26: 605-612.

20. Kelly FJ, Mudway I, Blomberg A, Frew A, Sandstrom T. Altered lung antioxidant status in patients with mild asthma. Lancet 1999; 354: 482-483.

21. Brown AA, Hu FB. Dietary modulation of endothelial function: implications for cardiovascular disease. Am J Clin Nutr 2001; 73: 673-686.

22. Mickle DA, Weisel RD. Future directions of vitamin $E$ and its analogues in minimizing myocardial ischemia-reperfusion injury. Can J Cardiol 1993; 9: 89-93.

23. Agler AH, Kurth T, Gaziano JM, Buring JE, Cassano PA. Randomised vitamin E supplementation and risk of chronic lung disease in the Women's Health Study. Thorax 2011; 66: 320-325.

24. Rahman I, Swarska E, Henry M, Stolk J, MacNee W. Is there any relationship between plasma antioxidant capacity and lung function in smokers and in patients with chronic obstructive pulmonary disease? Thorax 2000; 55: 189-193.

25. Tuder RM, Yoshida T, Arap W, Pasqualini R, Petrache I. State of the art. Cellular and molecular mechanisms of alveolar destruction in emphysema: an evolutionary perspective. Proc Am Thorac Soc 2006; 3: 503-510.

26. Messier EM, Mason RJ, Kosmider B. Efficient and rapid isolation and purification of mouse alveolar type II epithelial cells. Exp Lung Res 2012; 38: 363-373.

27. Faraonio R, Vergara P, Di Marzo D, Pierantoni MG, Napolitano M, Russo T et al. p53 suppresses the Nrf2-dependent transcription of antioxidant response genes. J Biol Chem 2006; 281: 39776-39784.

28. Cuadrado A, Rojo Al. Heme oxygenase-1 as a therapeutic target in neurodegenerative diseases and brain infections. Curr Pharm Des 2008; 14: 429-442.

29. Mercado N, Thimmulappa R, Thomas CM, Fenwick PS, Chana KK, Donnelly LE et al. Decreased histone deacetylase 2 impairs Nrf2 activation by oxidative stress. Biochem Biophys Res Commun 2011; 406: 292-298.

30. Qi H, Han Y, Rong J. Potential roles of PI3K/Akt and Nrf2-Keap1 pathways in regulating hormesis of Z-ligustilide in PC12 cells against oxygen and glucose deprivation. Neuropharmacology 2012; 62: 1659-1670.

31. Kosmider B, Messier EM, Chu HW, Mason RJ. Human alveolar epithelial cell injury induced by cigarette smoke. PLoS One 2011; 6: e26059

32. Sussan TE, Rangasamy T, Blake DJ, Malhotra D, El-Haddad H, Bedja D et al. Targeting Nif2 with the triterpenoid CDDO-imidazolide attenuates cigarette smoke-induced emphysema and cardiac dysfunction in mice. Proc Natl Acad Sci USA 2009; 106: 250-255.

33. Chen ZL, Tao J, Yang J, Yuan ZL, Liu XH, Jin M et al. Vitamin E modulates cigarette smoke extract-induced cell apoptosis in mouse embryonic cells. Int J Biol Sci 2011; 7: 927-936.

34. Zhuang J, Ma W, Lago CU, Hwang PM. Metabolic regulation of oxygen and redox homeostasis by p53: lessons from evolutionary biology? Free Radic Biol Med 2012; 53: 1279-1285.

35. Macip S, Igarashi M, Berggren P, Yu J, Lee SW, Aaronson SA. Influence of induced reactive oxygen species in p53-mediated cell fate decisions. Mol Cell Biol 2003; 23: 8576-8585.

36. You A, Nam CW, Wakabayashi N, Yamamoto M, Kensler TW, Kwak MK. Transcription factor Nrf2 maintains the basal expression of Mdm2: an implication of the regulation of p53 signaling by Nrf2. Arch Biochem Biophys 2011; 507: 356-364.

37. Kim HL, Seo YR. Molecular and genomic approach for understanding the geneenvironment interaction between Nrf2 deficiency and carcinogenic nickel-induced DNA damage. Oncol Rep 2012; 28: 1959-1967.

38. Rotblat B, Melino G, Knight RA. NRF2 and p53: Januses in cancer? Oncotarget 2012; 3 1272-1283.

39. Simbula G, Pibiri M, Sanna L, Cossu C, Molotzu F, Columbano A et al. The peroxisome proliferator BR931 kills FaO cells by p53-dependent apoptosis. Life Sci 2004; 75: 271-286.

40. Fiskin K, Ozkan A, Ayhan AG. Investigation of protective effects of selenium and vitamin $E$ against DNA oxidation, membrane damage and alteration of COMT metabolism in smoke-exposed male mice (Mus musculus, Balb/c). Acta Biol Hung 2006; 57: 403-413.

41. Koul A, Bhatia V, Bansal MP. Effect of alpha-tocopherol on pulmonary antioxidant defence system and lipid peroxidation in cigarette smoke inhaling mice. BMC Biochem 2001; $2: 14$.

42. Tsuda S, Matsusaka N, Ueno S, Susa N, Sasaki YF. The influence of antioxidants on cigarette smoke-induced DNA single-strand breaks in mouse organs: a preliminary study with the alkaline single cell gel electrophoresis assay. Toxicol Sci 2000; 54: 104-109.

43. Koul A, Singh M, Gangar SC. Modulatory effects of different doses of alpha-tocopherol on benzo(a)pyrene-DNA adduct formation in the pulmonary tissue of cigarette smoke inhaling mice. Indian J Exp Biol 2005; 43: 1139-1143.

44. Silva Bezerra F, Valenca SS, Lanzetti M, Pimenta WA, Castro P, Goncalves Koatz VL et al. Alpha-tocopherol and ascorbic acid supplementation reduced acute lung inflammatory response by cigarette smoke in mouse. Nutrition 2006; 22: 1192-1201.

45. Nardini M, Finkelstein El, Reddy S, Valacchi G, Traber M, Cross CE et al. Acrolein-induced cytotoxicity in cultured human bronchial epithelial cells. Modulation by alpha-tocopherol and ascorbic acid. Toxicology 2002; 170: 173-185.

46. de Batlle J, Barreiro E, Romieu I, Mendez M, Gomez FP, Balcells E et al. Dietary modulation of oxidative stress in chronic obstructive pulmonary disease patients. Free Radic Res 2010; 44: 1296-1303. 
47. Wu TC, Huang YC, Hsu SY, Wang YC, Yeh SL. Vitamin E and vitamin C supplementation in patients with chronic obstructive pulmonary disease. Int J Vitam Nutr Res 2007; 77: 272-279.

48. Itoh K, Chiba T, Takahashi S, Ishii T, Igarashi K, Katoh Y et al. An Nrf2/small Maf heterodimer mediates the induction of phase II detoxifying enzyme genes through antioxidant response elements. Biochem Biophys Res Commun 1997; 236: 313-322.

49. Kwak MK, Wakabayashi N, Itoh K, Motohashi H, Yamamoto M, Kensler TW. Modulation of gene expression by cancer chemopreventive dithiolethiones through the Keap1-Nrf2 pathway. Identification of novel gene clusters for cell survival. J Biol Chem 2003; 278 8135-8145.

50. Gill MB, Bockhorst K, Narayana P, Perez-Polo JR. Bax shuttling after neonatal hypoxiaischemia: hyperoxia effects. J Neurosci Res 2008; 86: 3584-3604.

51. Wesselkamper SC, Chen LC, Gordon T. Quantitative trait analysis of the development of pulmonary tolerance to inhaled zinc oxide in mice. Respir Res 2005; 6: 73.

52. Kosmider B, Loader JE, Murphy RC, Mason RJ. Apoptosis induced by ozone and oxysterols in human alveolar epithelial cells. Free Radic Biol Med 2010; 48: 1513-1524.

53. Wang J, Edeen K, Manzer R, Chang Y, Wang S, Chen X et al. Differentiated human alveolar epithelial cells and reversibility of their phenotype in vitro. Am J Respir Cell Mol Biol 2007; 36: 661-668

54. Balansky RM, DA F, De Flora S. Induction, persistence and modulation of cytogenetic alterations in cells of smoke-exposed mice. Carcinogenesis 1999; 20: 1491-1497.

55. Le A, Damico R, Damarla M, Boueiz A, Pae HH, Skirball J et al. Alveolar cell apoptosis is dependent on p38 MAP kinase-mediated activation of xanthine oxidoreductase in ventilator-induced lung injury. J Appl Physiol 2008; 105: 1282-1290.
56. Kosmider B, Osiecka R, Ciesielska E, Szmigiero L, Zyner E, Ochocki J. Induction of apoptosis and necrosis in lymphocytes by the cis-Pt(II) complex of 3-aminoflavone in comparison with cis-DDP. Mutat Res 2004; 558: 169-179.

57. Kosmider B, Zyner E, Osiecka R, Ochocki J. Induction of apoptosis and necrosis in A549 cells by the cis-Pt(II) complex of 3-aminoflavone in comparison with cis-DDP. Mutat Res 2004; 563: 61-70.

58. Ginzberg HH, Shannon PT, Suzuki T, Hong O, Vachon E, Moraes T et al. Leukocyte elastase induces epithelial apoptosis: role of mitochondial permeability changes and Akt. Am J Physiol Gastrointest Liver Physiol 2004; 287: G286-G298.

59. Votyakova TV, Reynolds IJ. Detection of hydrogen peroxide with Amplex Red: interference by NADH and reduced glutathione auto-oxidation. Arch Biochem Biophys 2004; 431: $138-144$

60. Kosmider B, Messier EM, Janssen WJ, Nahreini P, Wang J, Hartshorn KL et al. Nrf2 protects human alveolar epithelial cells against injury induced by influenza A virus. Respir Res 2012; 13: 13-43.

Cell Death and Disease is an open-access journal published by Nature Publishing Group. This work is licensed under a Creative Commons Attribution-NonCommercialNoDerivs 3.0 Unported License. To view a copy of this license, visit http://creativecommons.org/licenses/by-nc-nd/3.0/

Supplementary Information accompanies this paper on Cell Death and Disease website (http://www.nature.com/cddis) 